\title{
A Terminal Area Analysis of Continuous Ascent Departure Fuel Use at Dallas/Fort Worth International Airport
}

\author{
Keenan Roach ${ }^{1}$ \\ UARC/NASA Ames Research Center, Fort Worth, TX 76155 \\ John E. Robinson III $^{2}$ \\ NASA Ames Research Center, Moffett Field, CA 94035
}

\begin{abstract}
Aircraft departing from the Dallas/Fort Worth International Airport (DFW) encounter vertical restrictions that prevent continuous ascent operations. The result of these restrictions are temporary level-offs at 10,000 feet. A combination of flow direction, specific Area Navigation (RNAV) route geometry, and arrival streams have been found to be the biggest factors in the duration and frequency of a temporary level-offs. In total, $20 \%$ of DFW departures are affected by these level-offs, which have an average duration of just over 100 seconds. The use of continuous descent approaches at DFW are shown to lessen the impact arrivals have on the departures and allow more continuous ascents. The fuel used in a continuous ascent and an ascent with a temporary level-off have been calculated using a fuel burn rate model created from a combination of actual aircraft track data, aircraft manufacturer flight operations manuals, and Eurocontrol's Base of Aircraft Data (BADA) simulation tool. This model represents the average aggregate burn rates for the current fleet mix at DFW. Continuous ascents would save approximately seven gallons of fuel out of 450 gallons used to climb to a cruise altitude of $31,000 \mathrm{ft}$ per departure.
\end{abstract}

\section{Introduction}

$\mathrm{T}$ HE Next Generation Air Transportation System (NextGen) plan envisions managing increased traffic levels by using efficient trajectories that eliminate today's low-altitude delay absorption and level segments through continuous ascents and descents within the Terminal Radar Approach Control (TRACON) airspace ${ }^{1}$. In order to perform NextGen continuous departures and arrivals, tools and automation must be developed with procedures adapted for the individual structure of each TRACON.

Previous continuous descent and ascent studies have been completed, but the results have always been decoupled from each other. The fuel saving benefits of a Continuous Descent Approach (CDA) have been modeled, but are highly sensitive to trajectory changes and to any path deviations that result from merging or spacing maneuvers². Because of this sensitivity, many CDA trials have been completed during periods of low and moderate traffic ${ }^{3}$. Current CDA research is conducted at the limits of operational capability in order to include nominal traffic volumes $^{4,5}$. However, as CDA research continues, most efforts have not considered the impact of the new arrival procedures on the departures. Recent CDA results, focusing only on arrivals, may have room for yet undiscovered net gains in fuel savings, which would be achieved by optimized departure routes, made possible when arrivals fly higher.

DFW departures have been the subject of relevant research, but a current assessment of temporary level-offs and fuel usage has yet to be explored. Jung and Issacson studied the interaction between arrivals and departures at DFW for the development of the Expedite Departure Path (EDP) tool ${ }^{6}$. Their work mentions increased efficiency of uninterrupted climbs but does not include a fuel burn analysis. DFW has changed significantly since this work was completed; Area Navigation (RNAV) procedures have been implemented and are currently assigned to $95 \%$ of all

\footnotetext{
${ }^{1}$ Research Engineer, North Texas Research Station, 13800 FAA Rd., Senior Member AIAA.

${ }^{2}$ Aerospace Engineer, Aerospace High Density Operations Branch, MS 210-8, Senior Member AIAA.
} 
departing jets, peak rush periods have been eliminated by scheduling the arrivals and departures more evenly throughout the day, and Delta Air Lines no longer uses DFW as a hub airport. Current research work on DFW departures has focused on the use of RNAV procedures, specifically increased departure capacity and divergences from these routes ${ }^{7,8}$.

The aim of this study is to quantify the fuel savings through the use of continuous climbs to altitude by analyzing the temporary level-off segments of departures from DFW airport during nominal conditions. The level-offs are greatly influenced by the leveling of inbound arrivals at 11,000ft. CDA procedures would remove these low altitude level-off segments by elevating them to the arrival's cruise altitude, allowing a descent which is continuous from the top of the descent path to the final approach fix. An elevated arrival stream would lessen the impact of arrivals on the departures and likely permit departures to climb continuously on their route. Fuel burn calculations have been used to quantify the benefit of continuous ascents within the DFW TRACON.

\section{The Dallas/Fort Worth TRACON}

The DFW TRACON (D10) is designed as a four corner post airspace, roughly the shape of a square with each side 60 miles in length. D10's top boundary is 17,000 feet above mean sea level. Departing aircraft leave the TRACON to the north, south, east, or west, while arriving aircraft enter on the corners 9 . Figure 1 shows the D10 boundary with its departure and arrival fixes labeled. Departure fixes are in groups of four, called gates, e.g. LOWGN is on the north gate and NOBLY is on the east gate. While the horizontal tracks of the departures exit the TRACON via a departure fix, it is common for a departure to exit the TRACON through the top boundary instead of through a side. Departures are often handed off to the Fort Worth Air Route Traffic Control Center (ZFW ARTCC) prior to crossing a side boundary of the TRACON. Similarly to the departure fixes, the arrival fixes are in groups of three, with the exception of the southeast corner which has four arrival fixes.

The D10 TRACON contains 29 airports green.

within the DFW metroplex, with DFW being the dominate airport. A few of the other important airports are shown in Fig. 1. The D10 departure fixes serve residing airports with aircraft able to file capable flight plans. As a result of this ability, airports share the departure fixes. Arrivals enter the D10 TRACON over one of the four cornerposts and use the arrival fixes shown in Fig. 1. As this study's main focus is on south flow data, the primary arrivals analyzed are those using the southeast and southwest corners. These are the arrivals which level-off at 11,000ft after entering the TRACON. The 11,000ft level flight continues until the arrivals begin their downwind leg past DFW.

The departure fixes on the east and west sides of the TRACON can be divided into two groups based on their respective diverging RNAV departure paths. Figure 2 shows the inside (in blue) and outside (in red) tracks during south flow. The partial arrival routes from the south (in orange) show where arriving aircraft cross over the departure streams. In general, the inside track is the most desirable for east and west departures as it provides the shortest route to the departure fix. During periods of high departure rates, separation requirements necessitate the use of both tracks. However, when controllers deem it feasible, outside track departures commonly receive 
clearances to cut their route short by turning inside of their preplanned route $^{8}$. It has been previously mentioned that the departures are held under the arrival streams. Additionally, the length of the level-off is proportional to the particular track used. The inside tracks are not only shorter in overall length, but they also exit the altitude restrictions sooner than the outside tracks. This results in needing less time for the aircraft to spend level. Departures following the outside track without taking a shortcut exhibit the longest level-offs time periods.

\section{A. Temporary Level-Offs During Departures}

The low and slow level flight segments of an aircraft's trajectory have been shown to be significantly less efficient than unrestricted $\operatorname{climbs}^{6}$ and descents ${ }^{10}$. Since arrivals and departures share a common airspace, their trajectories are highly dependent upon each other. This interdependence creates the need to understand how

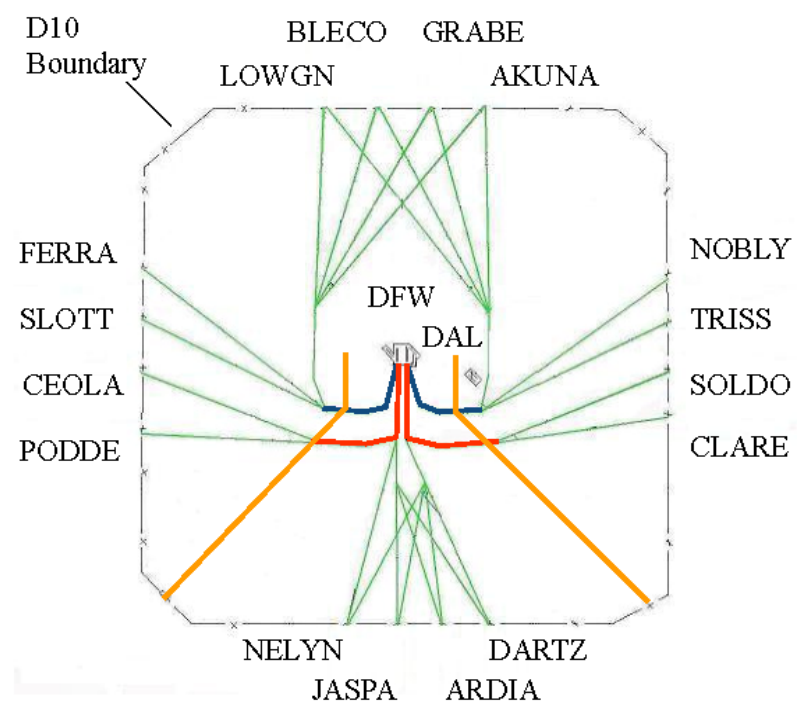

Figure 2. South flow DFW departure route crossings with southern arrival routes. current arrival streams and proposed CDA streams will affect the efficiency of departure climbs. Recent estimations of fuel consumption show a nominal climb/cruise/descent distribution of fuel use for a medium range flight of $1,000 \mathrm{~nm}$ is $20-25 \% / 65-75 \% / 5-10 \%$, respectively ${ }^{11}$. With the climb phase burning over twice the amount of fuel consumed during the descent, investigation into the benefit of uninterrupted climbs could hold considerable savings.

Departures within the DFW TRACON are given temporary level-offs when their tracks cross under arriving aircraft. These level-offs occur as directed by the departure procedures; "maintain 10,000[ft]. Expect filed altitude 10 minutes after departure", for all RNAV routes ${ }^{12}$. However, this compliance with procedure does not guarantee that a level-off will actually occur. Many flights receive clearance to climb to their filed altitude clearance before
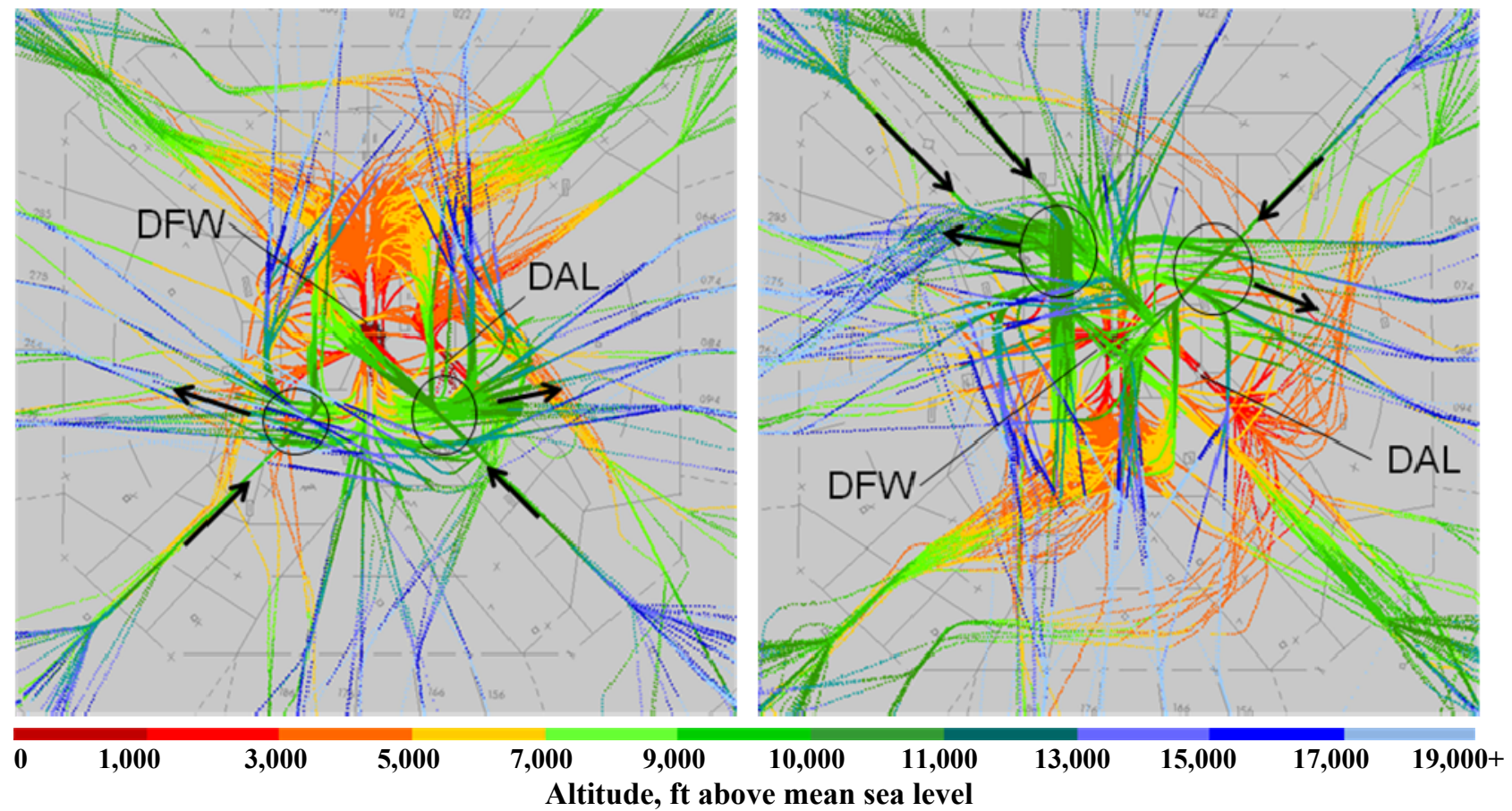

Figure 3. D10 TRACON track plots with altitude stratified by color. South flow (left) and north flow (right), American Airlines, American Eagle and Southwest Airlines flights only. Arrival/departure stream crossings of interest are indicated by the circles. Arrows designate aircraft stream direction of travel. 
they reach 10,000ft. A detailed analysis of these temporary level-offs provides a better understanding of why and where DFW departure level-offs occur. This insight helps highlight the areas of inefficiency, within the operational context of the terminal area.

The temporary level-off segments of interest to this study have been circled in Fig. 3, which shows traffic patterns at DFW in both south flow (left) and north flow (right). The tracks have been color coded by altitude in order to reveal which streams of traffic cross over or under others. The south flow configuration (i.e., departures and arrivals take off and land toward the south) is used approximately $70 \%$ of the time at $\mathrm{DFW}^{13}$. In this configuration, aircraft departing out of the south side of the TRACON have no arrival route crossings to restrict their ascents. Northbound departures cross under the southern arrivals and over the northern, lower, arrivals. A northbound departure's only level-off occurs as it passes under the southern arrivals, after which it climbs continuously out of the TRACON. East and west departures also cross under arrivals from the south before they continue ascending to their respective gates. All of these interactions are shown in Fig. 3. Traffic patterns during north flow are nearly a mirror image of those in south flow.

\section{B. Continuous Ascents Opportunities Made Available By CDA Operations}

Continuous descent trajectories at DFW present an opportunity for lifting restrictions on departure climbs. As mentioned earlier, departure restrictions hold aircraft at 10,000ft while arrivals fly level, above the departures, at $11,000 \mathrm{ft}$. CDA trajectories eliminate the $11,000 \mathrm{ft}$ level section by raising it to the cruise altitude. This, in effect, elevates the arrivals by $2,000 \mathrm{ft}$ to $4,000 \mathrm{ft}$ (depending on where the streams cross) above the departure stream. This elevation of the arrivals, in turn, lifts the level-off restriction on the departing aircraft and gives them more room to climb.

An example of these altitudes and their effects can be found in the CDA trial conducted at DFW on June 22, 2007. During this trial, an American Airlines flight performed a CDA over the southeast corner of the TRACON. Figure 4 shows the altitude profile of this flight (green) as it descends into DFW compared with a typical flight (red). The CDA flight was artificially elevated to a higher than normal cruise altitude $(34,000 \mathrm{ft})$ in order to simulate a longer flight with an extended descent path. The altitude profiles for each flight have been synchronized in time at the DIETZ waypoint in order to clarify the differences in the altitude profiles. The inset subplot shows the horizontal tracks and their relation to key waypoints and the D10 boundary. During south flow, DFW arrivals over the southwest corner post will typically descend to $11,000 \mathrm{ft}$ at TACKE and maintain level flight until DIETZ. At DIETZ, they begin their downwind leg and resume their descent. As denoted in Fig. 4, departures cross under the arrivals between the TACKE and DIETZ

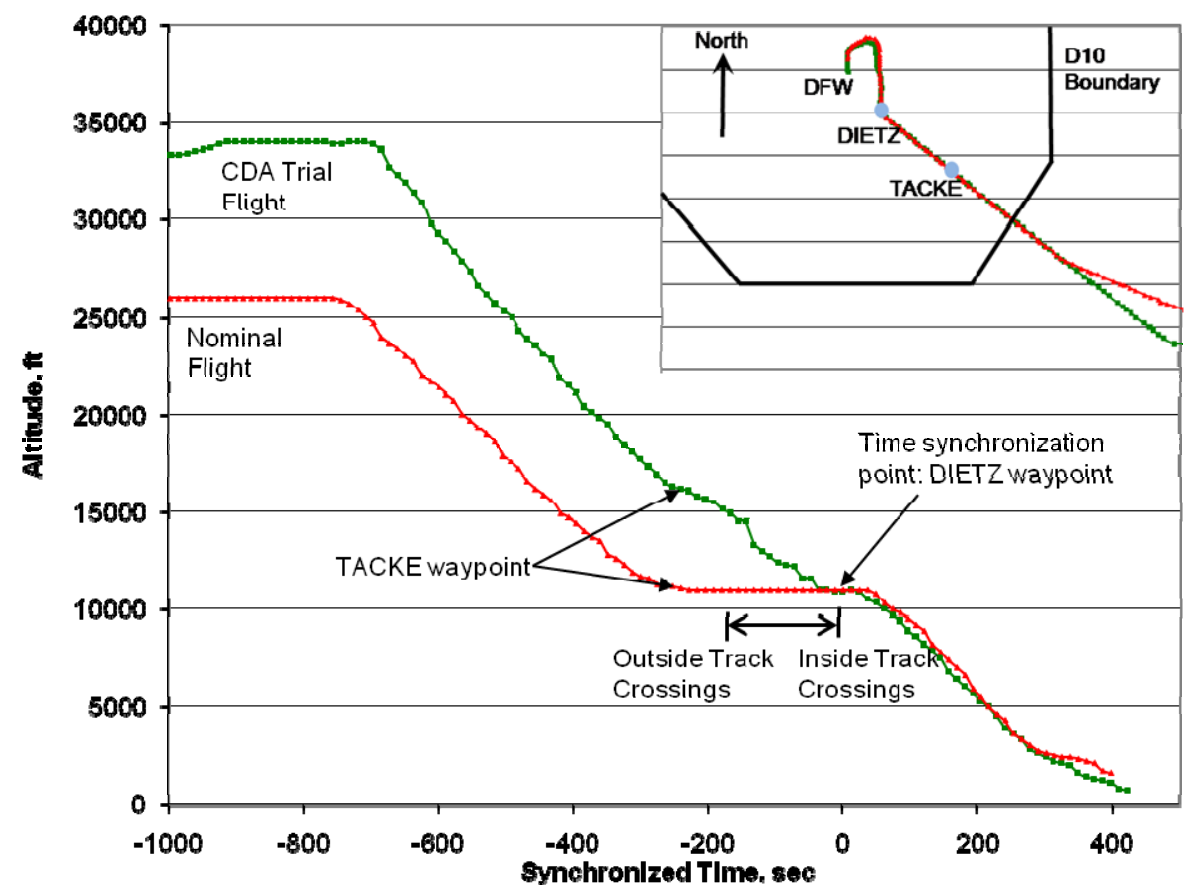

Figure 4. A comparison of descent trajectories between a nominal flight and a CDA trial. waypoints, heading to either 
the north or the east gates. Inside track departures cross close to DIETZ, while the outside track departures will cross further from DIETZ. See Fig. 2 for inside/outside track plots. Outside track crossing locations vary, since they are dependent upon the reduction in the length a route (if any) cleared by a controller. Inside track routes are shorter in overall path length, achieving smaller path length and lower fuel consumption. The closer an outside track departure is to its defined RNAV route, the less efficient it is and the longer its temporary level-off will be. CDAs would provide the most benefit to the outside track departures.

\section{Methodology}

For this study, nine days worth of data were chosen based upon their exceptional normality. Each day was clear, free of any convective weather, and DFW remained in a single configuration for the entire day. The data were collected at NASA's North Texas Research Station and is a compilation of DFW ASDE-X (surface and low-altitude tracks), DFW TRACON ARTS IIIe, and ZFW Host data. The Surface Operations Data Analysis and Adaptation (SODAA) tool ${ }^{14}$ and Matlab were used to analyze the data. The level-off sections were found using the IntentEngine, an offline post processing component of NASA's CTAS suite of tools. All level segments less than 30 seconds in duration were removed as statistical outliers.

The nine days, all from 2008, were split between north and south flow configurations. The five south flow days are: November 23 and 25 and December 7, 28, and 29. The four north flow days are: October 16, November 30, and December 1 and 11. During low traffic volume times (i.e. the late night and early morning hours) the constraints on TRACON traffic are relaxed, and planes are allowed to fly trajectories that are less rigid and optimized per individual plane as opposed to a system level basis. To capture the more realistic high traffic volume and rigid restrictions in the level-off analysis, traffic data from the hours of lower traffic was avoided and only high traffic volume data from 8:00 to 20:00 local time was used.

To accurately characterize level-off traits, the departures were first grouped by north and south flow and then further grouped by departure fix. To gain insight into the air traffic behavior of each flow-fix group, numerous plots of altitude profiles, starting and ending points of the level sections, and level sections segregated by aircraft type and by altitude range were created.

As this study's focus is on the aggregate fuel consumption, a fuel burn model was chosen that represented DFW traffic as a whole. EuroControl's BADA (Base of Aircraft Data) simulation tool was used to generate this model. The BADA results for different aircraft weight classes were verified using a combination of recorded track data and flight operations manuals from the manufacturer. Both level and climb fuel flow rates were found to be within $10 \%$ of each other. This suggests the BADA model is sufficiently accurate and capable of serving all the needs of this research. The BADA model accounts for fuel usage as an aircraft climbs by decreasing the mass of the aircraft proportionately to the amount of fuel used. A continuous climb with a nearly fully loaded aircraft was used as the initial condition. The weights at varying altitudes from the climb were then used to seed the level flight simulations which generated a family of fuel flow rates. The most important burn rates to study were those for the temporary level-off at $10,000 \mathrm{ft}$ and a level segment of equal length at the cruise altitude $(31,000 \mathrm{ft})$. All other segments of flight (climb, cruise, and descent) were assumed to be equal, resulting in the basis of this work being a comparison of level flight burn rates at those two altitudes at standard temperature and pressure with no winds.

\section{Results}

Section IV.A covers the characterization and analysis of the track data from aircraft whose climbs were restricted by a temporary level-off. The level-off durations are quantitatively detailed and trends associated with inside and outside RNAV routes are shown. Section IV.B contains the aggregate fuel burn analysis, including the intermediate results from individual aircraft that were used to validate the aggregate fuel burn model.

\section{A. Quantitative Characterization of the Temporary Level-Offs}

The first step in characterizing the $10,000 \mathrm{ft}$ level-offs in a sample of air traffic is to determine the individual flight capabilities of its constitutive aircraft and the structure of the airspace where the traffic is observed. Some 
aircraft types, such as small props and turbo props, do not have the necessary climb performance to be limited by an altitude climb restriction. In addition to the performance requirement, only jets are allowed to fly RNAV departure procedures. These restrictions are not a concern because according to subject matter experts, $95 \%$ of all DFW departures are jets flying RNAV routes. For this study, the data set consisted of roughly 3800 jets over the five south flow days. For departures using the east gate's four fixes, Fig. 5 illustrates the locations of the level-offs by means of a plot of the distance from DFW to the
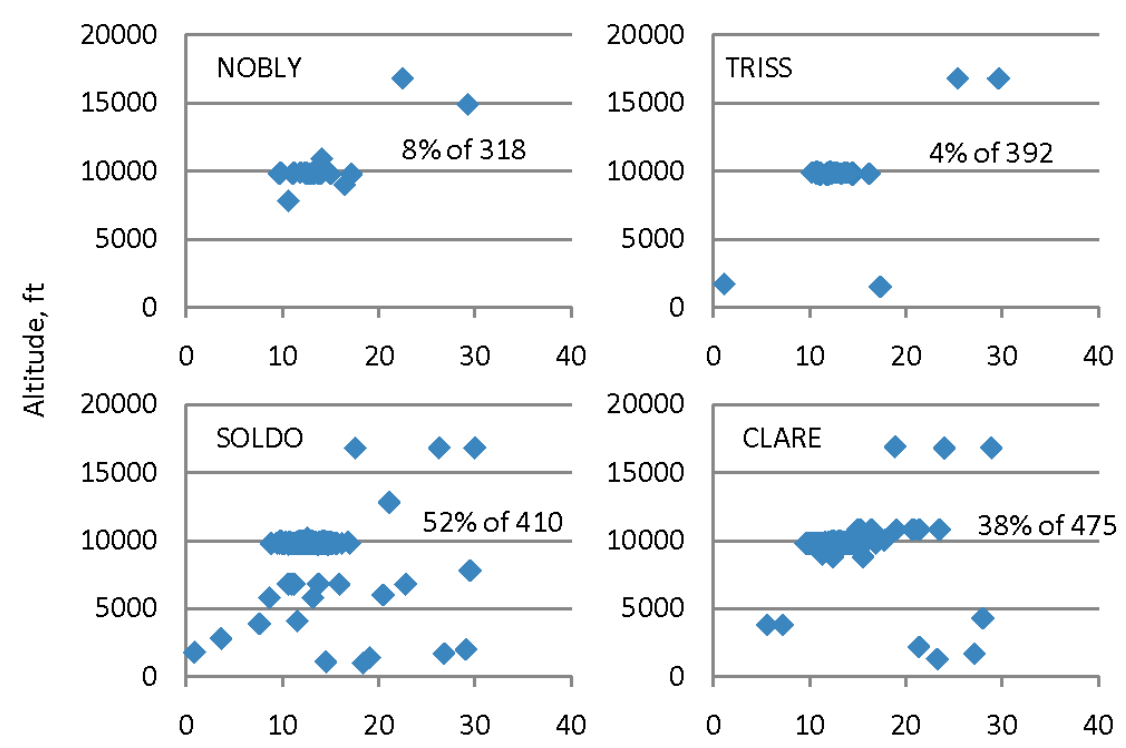

Distance from DFW to the start of level-off, $\mathrm{nm}$

Figure 5. South flow departure level-off starting points bound for the east gate fixes. The statistics indicate the percentage of 10,000ft level-offs per total number of departures crossing the respective fix.

starting point of the level section versus the altitude. The main comparison in this figure is between NOBLY and TRISS (inside track routes) and SOLDO and CLARE (outside track routes). All four fixes exhibit the level-off trend between 10 and 18 nautical miles from DFW, however the percentages of flights experiencing a level-off differ greatly between fixes. Less than $10 \%$ of NOBLY and TRISS departures are temporarily held at 10,000ft, while approximately half of SOLDO and CLARE departures are restricted. Similar results are found for the west gate departures. The two west gate outside track fixes (CEOLA and PODDE) each restrict about half of their respective flights. The large number of regional jets at DFW significantly influences the average aggregate fuel model, as will be seen in the following section. Because of this, the regional jets were originally plotted separately from the rest of the traffic mix, but their level-offs were no different, in terms of starting distance from DFW and altitude, than those of the larger jets.

With the knowledge of the flight capabilities and airspace behavior, the next step in the analysis is to understand the duration of the level-off. Figure 6 shows the number of level segments by altitude as well as statistical data for their durations for the SOLDO and NOBLY departure fixes. Both are on the east gate. SOLDO is on an outside track and NOBLY is on an inside track. Each level-off has been categorized into one of four bins, based on altitude ranging from 0 to 20,000ft. These are represented by the histograms in subplots A and B of Fig. 6 . As a single departure may have more than one level segment, the number of level-offs may be greater than the total number of departures. For each histogram bin, the durations of the level-offs have been represented by a set of statistics shown in subplots $\mathrm{C}$ and $\mathrm{D}$. The red boxes are the average duration for their respective bin. The max, min, median, and upper and lower quartile ranges have been displayed using a box and whisker plot. Both of these plots show the greatest number of level-offs occurring in the 5,001 to 10,000ft bins. The number of level-offs for the SOLDO fix (an outside track) are almost an order of magnitude greater than those of the NOBLY fix (an inside track). In addition, the average duration of the SOLDO route level-offs are nearly twice as long as those of NOBLY. Another quantity informative of arrival/departure interaction is the ratio of the number of $10,000 \mathrm{ft}$ level-offs to the total number of departures. The respective percentages of flights that experienced a level-off for SOLDO and NOBLY are $52 \%$ and $8 \%$. Similar results are seen for all outside and inside departure fixes. Overall, $40 \%$ to $50 \%$ of departures using an outside track have a 10,000ft level-off compared to 5 to $15 \%$ departures using an inside route. These data indicate that the departure route strongly influences the frequency and duration of the level-off. 
Figure 7 contains similar level-off statistical data that was provided in Fig. 6, however it is the comprehensive data set for the five south flow days for every departure fix. The key data points to be extracted are the average durations, but only when accompanied by a high percentage of restricted aircraft. SOLDO, CLARE, CEOLA, and PODDE makeup the highest percentage of the level-offs, lasting 1.7 minutes in duration, in the 5001$10,000 \mathrm{ft}$ subplot. Other durations can be found which are greater than 1.7 minutes, but their percentage of affected aircraft (generally less than $10 \%$ ) indicate that most of the departures are unrestricted. FERRA,
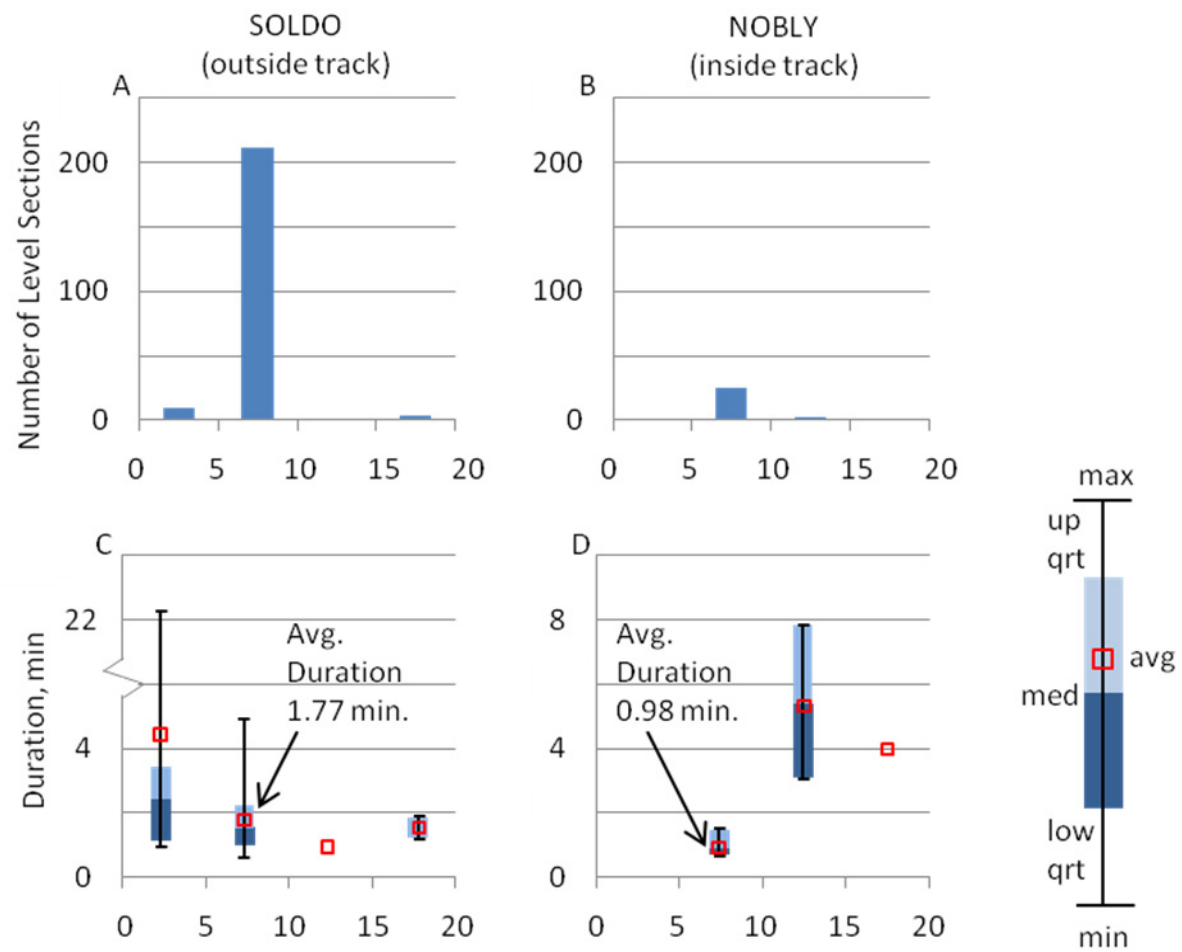

below 10,000ft, appears to be unusually restrictive for an inside track route. Upon further investigation, it was found that FERRA is heavily used by turbo props and small jets both flying short flights and the level-offs were not related to the incoming arrival stream. Overall, the four outside track fixes (SOLDO, CLARE, CEOLA, and PODDE) vertically restrict $20 \%$ of all departures from DFW.

During south flow operations, the four southern most departure fixes on the east and west gates have the only meaningful concentration of temporary level-offs at $10,000 \mathrm{ft}$. This is a result of two factors, the incoming arrival stream at $11,000 \mathrm{ft}$ and the geometry of the RNAV route. This section is concluded by discussing these two factors in detail.

The arrivals from the south level-off at $11,000 \mathrm{ft}$ force the departures to remain under the arrival stream. The decision to have the departing aircraft pass under the arrivals was made for safety, assuming the worst case climbing condition: a poorly performing and heavy aircraft on a hot day. Having to accommodate all aircraft, including the worst-case, the procedures were designed with vertical limits. Results from prior analysis of limited flights show that CDA procedures remove the level segments of arrivals by lifting the stream above $11,000 \mathrm{ft}$. This, if implemented, would raise the altitude restriction for departures and decrease the frequency and duration of level-offs during climbs. Essentially, CDA procedures at DFW would help the departures become more efficient by relaxing the vertical restrictions. The RNAV route geometry was designed to provide adequate spacing between aircraft while maximizing the departure rate by alternating inside and outside track usage. This design inherently stretched the path of the outside track, allowing the departures to reach the $10,000 \mathrm{ft}$ limit before they emerge from under the arrival stream. This selective path stretching explains why a strong trend to level-off under the arrivals is observed only in the outside track departures. 

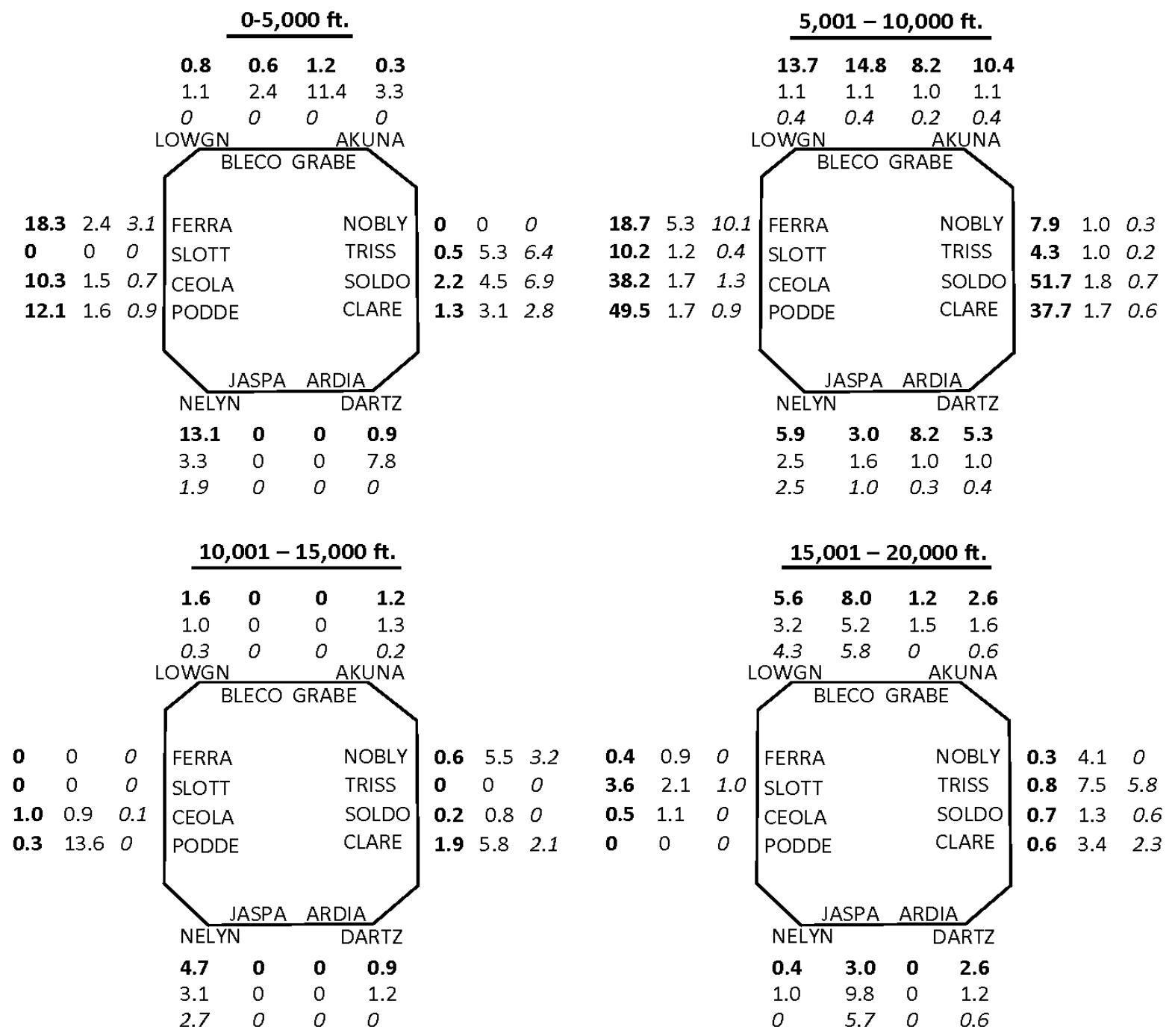

\% of Level-offs per Total Departures Average Duration and Standard Deviation, min

Figure 7. South flow departure level-off statistics by fix and altitude band. For each altitude range, a D10 boundary has been provided with the appropriate departure fixes labeled. For each departure fix, the percentage of level-offs per total number of departures, the average duration of the level-offs in minutes, and the standard deviation in minutes have been provided.

\section{B. Average Aggregate Fuel Burn for DFW}

In order to make general statements about fuel burn rates for the entire DFW TRACON airspace, a model was chosen which represents the theoretical average aircraft for the traffic mix of the airspace instead of an individual aircraft. Ideally, live aircraft data would be used to generate this model, but fuel burn rate data are unavailable from this data source. Eurocontrol's BADA simulation tool was used to extract fuel burn rate data. A combination of actual aircraft data and aircraft manufacturer flight operations manuals were used to characterize the accuracy of BADA. Altitude and true airspeed versus time were compared between all three data sources. The takeoff weight and speed found in the BADA and flight operations manuals were adjusted in order to have the climb rates and true airspeeds match that of the actual aircraft data. The extracted takeoff weights and air speeds were used to seed the BADA model's initial conditions. With the altitudes and true airspeeds matched between all three data sources and 
the fuel burn rates matched between two of the data sources, the assumption was made to accept the matching fuel burn rates as accurate.

The dependence of an aircraft's nominal air speed on the altitude hinders a comparison of fuel flow rates at varying altitudes. Usually, an aircraft's air speed is greater at higher altitudes than at lower altitudes. In order to normalize the fuel usage, Fig. 8 shows the fuel consumption rate for one nautical mile of level flight at varying altitudes. Also, as an aircraft climbs and burns fuel, its weight decreases. In order to account for these changing states, the weights and air speeds used for each point in Fig. 8 were taken from a climb simulation at each respective altitude. For example, beginning with an

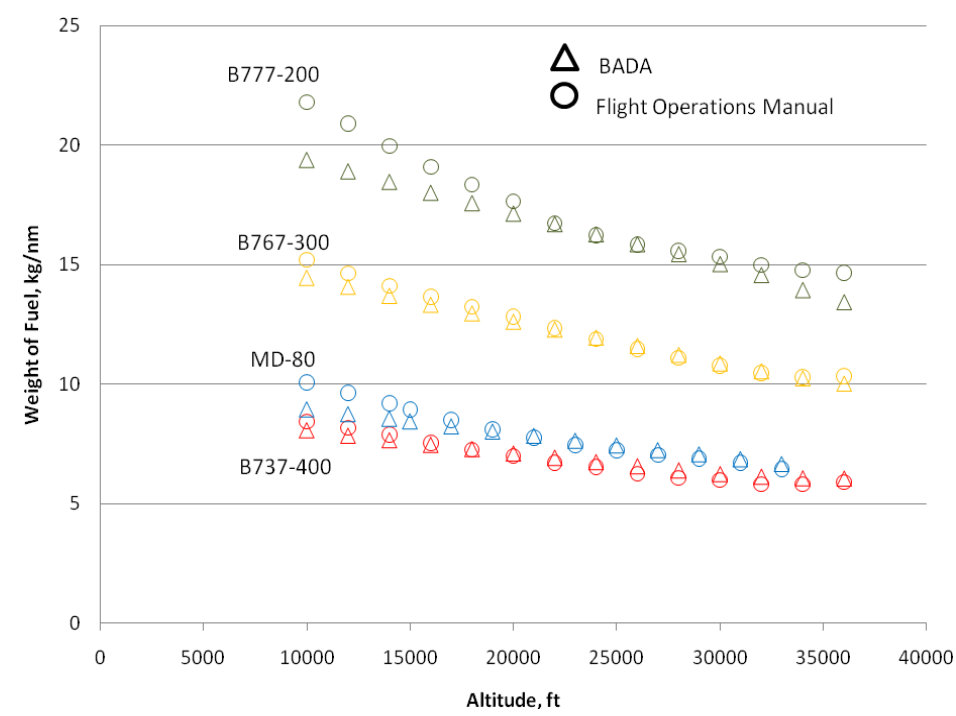

Figure 8. Fuel consumption for $1 \mathrm{~nm}$ of level flight as predicted by flight operations manuals and BADA. initial takeoff weight of $62,000 \mathrm{~kg}$, by $10,000 \mathrm{ft}$ the weight of the Boeing $737-400$ was $61,502 \mathrm{~kg}$ and its air speed was Mach 0.52. At 36,000ft, the weight and air speed were 60,287 kg and its Mach 0.74, respectively. The results of the comparison between flight operation manuals and BADA indicated that BADA is sufficiently accurate to simulate fuel usage, with the greatest discrepancy of 10\% belonging to the Boeing 777-200 at 10,000ft.

Once the BADA model's accuracy had been characterized for level flight fuel burn estimations, it was used to determine the aggregate fuel burn rates of all DFW traffic. First, the aircraft types and the number of aircraft of each type were extracted from the archived data. The top aircraft types (representing $95 \%$ of all DFW traffic) were then modeled in BADA and their fuel burn rates were plotted against altitude, see Fig. 9. Each aircraft type in this figure has been ranked by order of occurrences in the legend. The average aggregate fuel burn curve, generated from each individual aircraft burn rate and weighted by its frequency, is shown as a solid line. One coincidental trait of the DFW aggregate burn rate is how well it matches that of a Boeing 737-400. The B737-400 currently represents less than $1 \%$ of the traffic mix at DFW; however, it is nearly a perfect match to the average fuel flow for the current aircraft mix. The Boeing 737-400 model can be used within BADA to evaluate

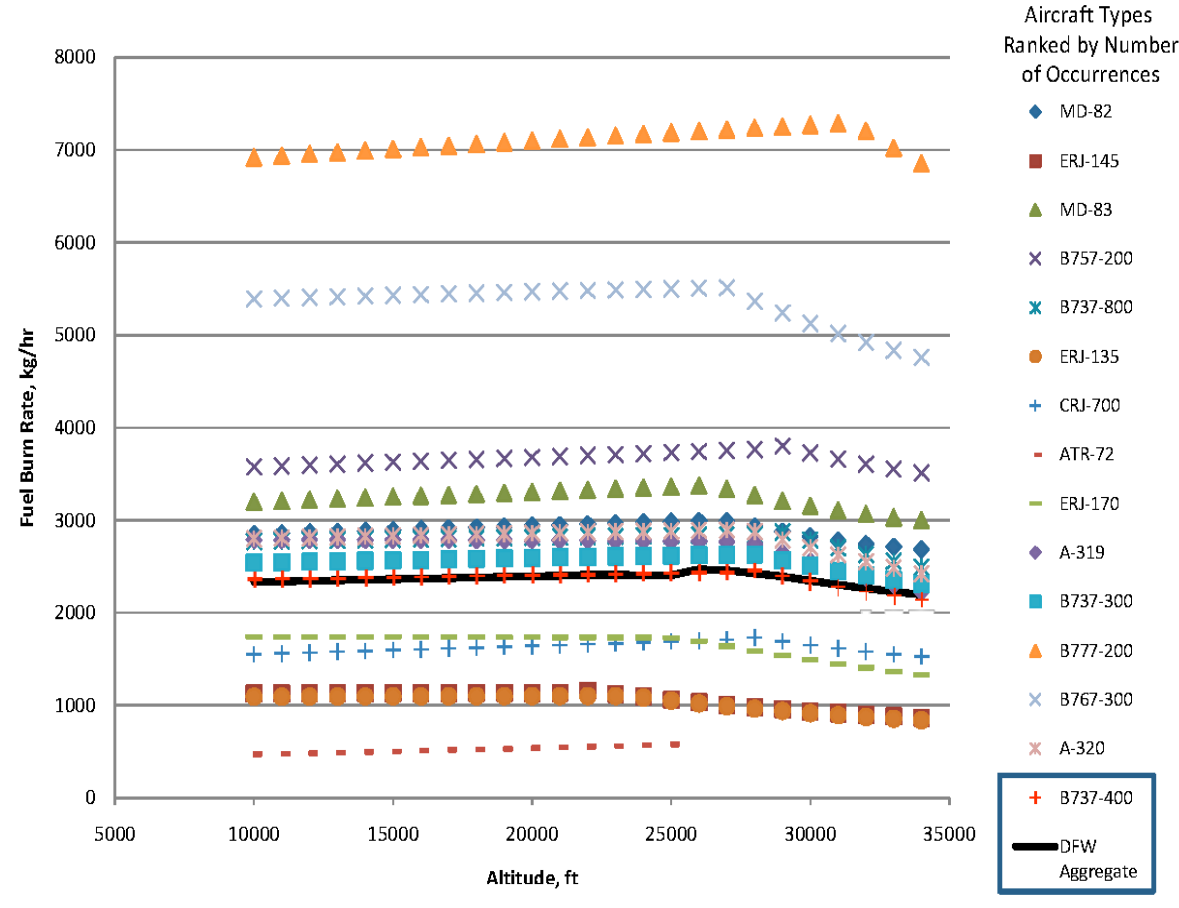

Figure 9. Fuel burn rates at varying altitudes for DFW aircraft types. The average fuel burn for the aggregate DFW traffic mix is shown by the solid black line. 
modifications to the DFW airspace, specifically the terminal airspace.

Comparing the efficiency of a continuous ascent departure route to that of a nominal route, with a temporary level-off, amounts to comparing fuel burn for a level flight segment at $10,000 \mathrm{ft}$ versus one at a higher altitude. The savings can be looked at in two ways: fuel based savings and time based savings.

Fuel based savings are achieved by replacing the inefficient "low and slow" segment with a cruise segment of equal distance, see Fig. 10. In this figure, the red and blue altitude profiles represent, respectively, the low altitude level-off and the continuous ascent. For this simulation, a cruise altitude of $31,000 \mathrm{ft}$ was chosen because it was found to be the average cruise altitude for the top air carriers at DFW. The three variables are altitude,

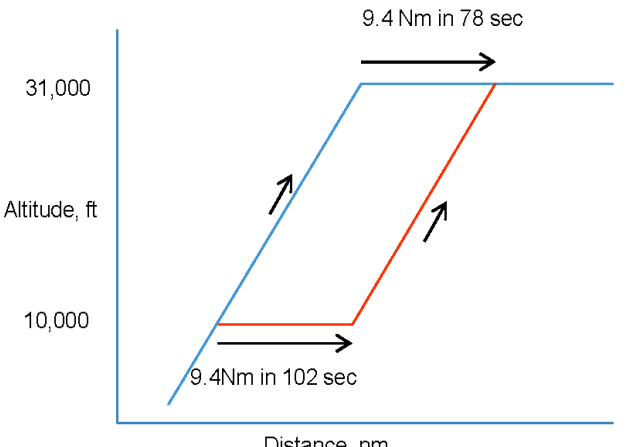

Distance, $\mathrm{nm}$

Figure 10. DFW departure route with temporary level-off (in red) and continuous ascent route (in blue). fuel flow rate, and speed. At low altitudes the fuel flow rate is less, but so is the speed. To reduce the dimensionality of the model, the fuel usage has been normalized to the amount used to fly $1 \mathrm{~nm}$. The average duration of a $10,000 \mathrm{ft}$ level-off was found to be 1.7 minutes, over which time the average DFW aircraft will fly for $9.4 \mathrm{~nm}$, based on the air speed of $331 \mathrm{kts}$ given by the BADA model. The trajectory based savings are a result of the difference in fuel consumed per mile at the different altitudes, in this case $8.0 \mathrm{~kg} / \mathrm{nm}$ at $10,000 \mathrm{ft}$ and $6.2 \mathrm{~kg} / \mathrm{nm}$ at $31,000 \mathrm{ft}$. The average DFW departure with a temporary level-off will use approximately $1,395 \mathrm{~kg}$ (450 gallons) of fuel to climb to an altitude of $31,000 \mathrm{ft}$. The total average fuel savings per flight for a continuous ascent is approximately $22 \mathrm{~kg}$, or 7 gallons based on a jet fuel weight of $3.1 \mathrm{~kg}$ per gallon.

The time based savings are a result of the total flight time being reduced by flying the $9.4 \mathrm{~nm}$ section at $437 \mathrm{kts}$ at $31,000 \mathrm{ft}$ instead of at $331 \mathrm{kts}$ at $10,000 \mathrm{ft}$, resulting in total flight time that is 24 seconds shorter. Figure has denoted the flight times for the low and cruise level altitudes. While time savings are a benefit, half a minute is nominal at best. The results of both fuel and time savings are shown in Table 1. Using the Boeing 737-400 as the typical DFW departing aircraft, BADA and flight operation manual estimations have been tabulated.

Table 1. Estimated potential fuel savings with continuous ascent operations at DFW based on BADA and Flight Operation Manual data.

\begin{tabular}{|c|c|c|c|c|c|c|}
\hline & $\begin{array}{c}\text { Altitude } \\
\mathrm{ft}\end{array}$ & $\begin{array}{c}\text { Air Speed } \\
\text { kts }\end{array}$ & $\begin{array}{c}\text { Fuel used } \\
\text { to fly } \\
9.4 \mathrm{~nm} \\
\mathrm{~kg}\end{array}$ & $\begin{array}{l}\text { Time to } \\
\text { fly } \\
9.4 \mathrm{~nm} \\
\mathrm{sec} \\
\end{array}$ & $\begin{array}{l}\text { Fuel } \\
\text { Savings } \\
\text { kg (gal) }\end{array}$ & $\begin{array}{c}\text { Time } \\
\text { Savings } \\
\text { sec } \\
\end{array}$ \\
\hline \multirow[t]{2}{*}{ BADA } & 10000 & 331 & 76 & 102 & $0(0)$ & 0 \\
\hline & 31000 & 437 & 58 & 78 & $18(6)$ & 24 \\
\hline Operations & 10000 & 331 & 79 & 102 & $0(0)$ & 0 \\
\hline Manual & 31000 & 437 & 55 & 78 & $25(8)$ & 24 \\
\hline
\end{tabular}

\section{Conclusion}

Nine days worth of DFW actual aircraft data, resulting in 3,836 south flow departures, were analyzed. The vertical restrictions on departures were characterized and found to arise from the local RNAV routing and interactions with arrival streams. These temporary level-offs, lasting an average of 1.7 minutes, affect 20\% DFW's departing aircraft, all of which are assigned an outside track RNAV route. CDA operations at DFW would offer an opportunity for departures to climb with relaxed vertical restrictions. This is a result of the increased altitude of the arrival stream crossing over the departures.

Actual aircraft data and flight operations manuals were used to validate the fuel burn estimations of Eurocontrol's BADA simulation tool. The BADA estimations were found to be within $10 \%$ of the flight operations 
manuals burn rates at low altitudes and much closer at altitudes above 20,000ft. These results provided the confidence to use the BADA model's estimations for level flight fuel burn rates without the use of a correction factor. A fuel burn rate model was created based on the average aggregate fuel burn rate of the entire DFW traffic mix. The Boeing 737-400's burn rate happened to be a nearly perfect match to that of the average aggregate traffic mix of DFW, and was used in BADA to generate data for the simulation. The fuel savings from the optimized departure trajectories at DFW are approximately seven gallons per aircraft. Although the time savings achieved by a shortened flight time were only nominal, they do highlight the sensitivity of trajectory optimization with regards to schedule. Any benefit from a continuous ascent operation would be significantly affected by a delay of half a minute during its cruise. This result highlights the importance of meeting schedules and minimizing delays.

Future work will include looking at other TRACONS (Atlanta and Northern and Southern California) to see how their local conditions are restricting departures and what impacts CDAs might have on them. Average aggregate fuel burn models will be generated based on the fleet mix at each TRACON in order to calculate the fuel burn impacts of simulated route changes.

\section{References}

1.“NextGen Concept of Operations v2.0," Joint Planning and Development Office, June 13, 2007.

2.Weitz, L; Hurtado, J; Baramore, B; Krishnamurthy, K, “An Analysis of Merging and Spacing Operations with Continuous Descent Approaches", Digital Avionics Systems Conference, October 2005.

${ }^{3}$ Clarke, J; et al, "Development, Design, and Flight Test Evaluation of a Continuous Descent Approach Procedure for Nighttime Operation at Louisville International Airport", Partnership for Air Transportation Noise and Emissions Reduction, January 9, 2006.

4. Tong, K; Schoeming, E; Boyle, D; Scharl, J; Haraldsdottir, A, "Descent Profile Options for Continuous Descent Arrival Procedures Within 3D Path Concept," 26 ${ }^{\text {th }}$ Digital Avionics Systems Conference, October 2007.

${ }^{5}$ Coppenbarger, R., Mead, R., Sweet, D., "Field Evaluation of the Tailored Arrivals Concept for Datalink-Enabled Continuous Descent Approach,” Aviation Technology, Integration and Operations Conference, September 2007.

6.Jung, Y; Isaacson, D, "Development of Conflict-Free, Unrestricted Climbs for a Terminal Area Departure Tool," Aviation Technology, Integration and Operations Conference, November 2003.

${ }^{7}$ Mayer, Ralf H., and Kevin R. Sprong, 2008, "Improving Terminal Operations - Benefits of RNAV Departure Procedures at Dallas-Fort Worth and Hartsfield-Jackson Atlanta International Airports," Aviation Technology, Integration, and Operations Conference, September 2008.

${ }^{8}$ Borchers, P; Day, K, "Analysis of Divergences from Area Navigation Departure Routes at DFW Airport," $27^{\text {th }}$ Digital Avionics Systems Conference, October 2008.

${ }^{9}$ DFW Air Traffic Control, Department of Transportation, Federal Aviation Administration, Order DFW 7110.65H

10. Wilson, I; Hafner, F, "Benefit Assessment of Using Continuous Descent Approaches at Atlanta," Digital Avionics Systems Conference, October 2005.

${ }^{11 .}$ Robinson, J; Kamgarpour, M, “Analysis of Vertical Efficiency of TRACON Operations," To be published at the Aviation Technology, Integration and Operations Conference, September 2010.

12. FAA, Dallas/Fort Worth International Airport, "AKUNA TWO DEPARTURE (RNAV)," SC-2, Departure Route Description, December 2009.

13. Roach, K, "Procedures and Issues of a Restrictive Runway Configuration at Dallas/Fort Worth International Airport," Modeling and Simulations Technologies Conference, August 2007.

14. SODAA, Surface Operations Data Analysis and Adaptation tool, Software Package, Version 2.1, Mosaic ATM, Leesburg, VA, 2009. 